\title{
Envisioning the future
}

\section{Circuit}

By Daniel K. Blewett

\section{Creating the bumanities classroom of the 21st century}

B eautiful weather was the rule for this exciting conference held at Michigan State University (MSU) in East Lansing, Michigan, on Sept. 25-28, 1997. Sponsored by the National Endowment for the Humanities and the Humanities Network (based at MSU), nearly 150 people attended workshops, panels, and discussion groups.

Many of those present are on the cutting edge of developing electronic course materials, while others were there to gain new ideas and insights. Most of those attending were from colleges and universities, with a few librarians and fewer elementary or secondary education teachers. While there were some presentations of compact disc products, most participants were interested in how the Internet could be integrated into educational settings.

Two of the issues directly addressed were using electronic materials as a way of sharing information resources, and as a part of distance education. The role of librarians in this brave new world was addressed in a panel discussion on "Faculty-Library Partnership in the Digital Age: Linking to the Classroom." At this session Cheryl Malone, of the University of Illinois Graduate School of Library and Information Science, read a paper entitled "Librarian as Link: An Information Literacy Perspective." However, librarians will have to expend more effort to make sure that they are included in these projects.

Other sessions focused on topics such as "Building Critical Thinking Skills," "The Liberation and Constraints of New Learning Tech- nologies," and "Teaching the Teacher of the 21st Century."

The use of electronic information already available from federal and state governments, such as from the Library of Congress, the Census Bureau, and the National Archives, was mentioned but not explored in the depth that it could have been. Just like in our libraries. frustrating and embarrassing technical glitches meant that equipment and systems could not be used when they were most needed. But everything worked well for the electronic poster session held in an well-equipped MSU Education Department computer lab, where presenters were able to demonstrate their successful projects to smaller groups.

What is clear from these discussions is that any new project requires time, money, administrative support, teacher interest, along with adequate computer equipment and technical support. Many institutions or individuals cannot muster the needed support to develop their own products, and so must be able to adapt to what is already available to meet their needs.

This was a well-planned and thought-provoking conference. According to the introductory page of the program, this conference was "the culmination of a three year H-Net project to investigate, evaluate and disseminate information alsout the applications of new technology in teaching." H-Net's teaching networks (H-Teach, H-MMedia, H-Survey, H-WCiv, HTeachP'ol, H-AfrTeach) and subject networks are places to look for further information on this topic.

Proceedings of the conference will eventually be published, but details have not yet been finalized. For those who are interested, the Web site for the conference is http://www.hnet.msu.edu/renvision/ 